\title{
MAX Weber e A OBJETIVIDAde NAS CIÊNCIAS SOCIAIS
}

\author{
Carlos Vasconcclos Rocha
}

A história das Ciências Sociais é, em certo aspecto, a tentativa de reproduzir a objetividade alcançada pelas ciências naturais. Tal esforço não alcançou resultados satisfatórios e provavelmente nunca alcançará. O problema é que nas ciências sociais há uma identidade, ainda que parcial, entre o sujeito e o objeto: o processo de conhecimento científico é ele próprio um fato humano, histórico e social. Ao contrário, nas ciências naturais há um acordo real e implícito a respeito do valor, da natureza e do fim da pesquisa. Isto significa que o conhecimento adequado e eficaz nas ciências naturais é um ideal que não choca interesses e valores.

O dilema colocado para as ciências sociais é que se todo pensamento científico visa alcançar nas suas teses o valor de verdades objetivas, desafortunadamente o conhecimento do social tende ${ }^{1}$ a ser impreg-

${ }^{1} \mathrm{~A}$ influência dos valores nas ciências sociais é tida como maior ou menor conforme as posições epistemológicas dos autores. Mesmo para os autores positivistas, o problema da influência da subjetividade na pesquisa está colocada. Para estes, porém, há a crença na neutralização de tal influência.

Temáticas, Campinas, 3(5/6):37-53, jan./dez. 1995 
nado pela subjetividade do cientista ou, em outras palavras pelos seus juízos de valor.

Um exemplo privilegiado de tal dilema pode ser encontrado nas obras de Max Weber, onde é clara a tensão entre objetividade e subjetividade ou ciências humanas e ciências naturais. A expressão que tal tensão toma na obra de Weber pode ser explicada, talvez, pelo contexto em que é escrita. Weber escreve em um ambiente de abalo na concepção positivista do mundo, onde já circulavam as idéias de Freud e Nietzsche, por exemplo, e onde a crença na ordem racional do mundo entra em crise e o fosso entre "world of being" e "world of meaning", ou objeto e analista, parece intransponível (Kasler, 1979). Os parâmetros que informam o pensamento de Weber, portanto, são, de um lado, a busca do conhecimento objetivo, e, de outro, a sensação da impossibilidade de alcançar tal intento.

Este trabalho pretende abordar o tema de objetividade e da subjetividade nas ciências sociais, através da forma como Weber elabora a questão. Partiremos da hipótese de que a obra de Weber guarda com relação ao assunto uma incoerência interna. Buscaremos demonstrar tal afirmação através da análise comparativa de dois de seus trabalhos. Posteriormente, discutiremos os comentários de alguns autores sobre as idéias de Weber. E finalmente, entraremos no mérito das conclusões do autor.

\section{II}

Uma das manifestações, no trabalho de Weber, do tema da objetividade e subjetividade nas ciências sociais, ${ }^{2}$ é o da relação entre política e ciência, cuja abordagem torna-se clássica na sociologia. Com o

${ }^{2}$ Weber utiliza, em suas obras, termos como "economia social", "ciências históricas", "ciências da cultura", que podem ser tomados como equivalentes ao que hoje é denominado de ciências sociais.

Temáticas, Campinas, 3(5/6):37-53, jan./dez. 1995 
"desencadeamento do mundo", abalados os "mitos" e "ilusões" das explicações mágicas e religiosas, esvai-se o fator de suporte dos regimes políticos e aumenta a colisão de valores. Coloca-se a questão da indeterminação dos valores públicos e o problema das bases para a sua determinação. A relação entre poder e conhecimento torna-se trágica, dada a virtual legitimidade de uma ampla gama de valores. O predicado do mundo moderno é um mundo sem mito, onde a ciência derruba as formas de mitos do pensamento político e cria um fosso entre conhecimento $\mathrm{c}$ ação. Partindo destas idéias, Weber, $\mathrm{cm}$ A Ciência como Vocação, procura distinguir as esferas da ciência e da política, do pensamento e da ação. Vejamos como procede.

A partir da abordagem comparativa do sistema universitário alemão e americano, sua estrutura organizacional e as condições materiais do exercício da ciência $\mathrm{em}$ ambos os países, Weber tece considerações sobre a ciência e sua relação com os valores ou a política. Afirma que as realizações científicas são voláteis, pois "toda realização científica suscita novas perguntas: pede para ser ultrapassada e superada" (1971, p. 164). É um fato a que se tem que resignar. O conhecimento busca sempre superar-se no sentido de um progresso que se faz ad infinitum. O que coloca a questão da significação da ciência. A ciência ganha significado, por um lado, visando finalidades práticas ou técnicas. Para o cientista, porém, que não encontra sentido em tal explicação - pois, faz sentido para os "homens práticos" - o que significa a ciência? É o que o autor busca responder.

"Por "desencantamento do mundo" Weber designava a passagem de um mundo em que a explicação dos fenômenos da vida e da natureza tinha base religiosa, um mundo em que todas as coisas tendem a ser abordadas pelo cálculo racional. Neste sentido, a característica básica do mundo ocidental moderno é que os princípios racionais organizam e dotam de gerência as diferentes esferas da organização social.

Temáticas, Campinas, 3(5/6):37-53, jan./dez. 1995 
O progresso científico é a parte mais importante do processo de racionalização do mundo moderno. Seu pressuposto é a idéia de que podemos dominar todas as coisas pelo cálculo, o que não indica, porém, um conhecimento maior das condições sobre as quais vivemos. Um selvagem, exemplifica Weber, tem um conhecimento muito maior sobre as ferramentas que utiliza, do que um passageiro tem sobre o bonde que o transporta (1971, p. 165).

Desta forma, depois de desaparecidas as ilusões da ciência como caminho para o verdadeiro Deus ou para a verdadeira felicidade, ela não responde a única pergunta importante para nós: o que deveríamos fazer e como devemos viver? Ou seja, não pode oferecer sentido à nossa vida ou, de outra forma, os valores pelos quais deveríamos pautar nossa ação.

Tal diagnóstico é a base para a cisão entre as esferas dos valores e da ciência, e para sua proposta de uma ciência livre de pressuposições valorativas. Transpostas tais constatações para a relação da política com a cátedra, o autor ressalta que é diverso o ato de tomar uma posição política prática da análise política propriamente dita. O que cabe ao professor, portanto, é a exposição isenta dos fatos, em seus diversos aspectos e perspectivas. Uma intervenção que caberia aqui, e cuja resposta buscaremos dar ao longo deste trabalho, é se tal proposição é possível de ser realizada.

Um desdobramento específico da proposta Weberiana é o argumento de que se a recusa em abordar os valores na sala de aula, por um lado, está fundada na posição de que estas transcendem a esfera da ciência, por outro lado, referindo-se ao caso alemão, justifica que na sala de aula os alunos não têm a permissão da palavra. Desta forma, os professores poderão expressar suas opiniões políticas apenas fora da sala de aula. Aqui Weber, ao buscar resguardar a igualdade das partes (alunos e professores) frente aos valores, comete um erro: ao invés de suspender a 
discussão, numa situação em que uma das partes é privada da palavra, o necessário seria, ao contrário, inflá-la.

Apesar de propor a cisão das esferas dos valores e da ciência, Weber é ciente da complexidade de sua proposta. Isto fica claro quando ressalta o caráter subjetivo da ciência. Afirma que os pressupostos da ciência escapam ao seu controle. Por exemplo, o pressuposto de que vale a pena conhecer as leis dos acontecimentos cósmicos não pode ser validado cientificamente. Assim, a ciência se faz sobre a eleição de valores, baseados na sua significação, que não podem ser validados cientificamente. Ainda assim, afirma que "é, sem dúvida, possível que o professor individual não consiga eliminar totalmente suas simpatias pessoais" (1971, p. 173), mas sua tarefa é procurar fazê-lo.

Qual é a contribuição, então, que a ciência pode trazer para a vida prática? Segundo Weber, pode contribuir fornecendo tecnologia, oferecendo métodos de pensamento e, finalmente, permitindo a clareza. Explica que as atitudes possíveis diante da vida são várias e inconciliáveis, sendo que a luta entre os valores nunca chega a uma conclusão. Este relativismo redunda na situação onde a necessidade de escolha entre a gama de valores possíveis é um imperativo. Como a ciência não pode ser parâmetro para orientar tal escolha, fica retratada a situação de abandono típica da filosofia existencialista. Diante de tal situação, o que a ciência pode oferecer são os instrumentos ou métodos para averiguar se, ao implementar-se uma convicção, os meios inevitáveis compensam dada decisão. Desta forma, a ciência "livre de pressuposições" deve servir às pessoas, independente das perspectivas em que estas últimas se encontram (tanto a um católico, como a um maçom, por exemplo). O valor do fim em si não entra nas considerações da ciência, ou seja, a base valorativa de uma posição não pode ser julgada objetivamente. ${ }^{4}$

${ }^{4}$ Ver crítica sobre a posição de Weber em Aron (1986).

Temáticas, Campinas, 3(5/6):37-53, jan./dez. 1995 
A ciência, portanto, não é capaz de dar resposta a que valores eleger - não o cientista, mas o líder carismático é que pode cumprir esse papel -, constituindo-se apenas em "uma 'vocação' organizada em disciplinas especiais a serviço do auto-esclarecimento c conhecimento de fatos inter-relacionados" (Weber, 1971, p. 180). O papel do cientista é, segundo suas palavras,

"forçar o indivíduo, ou pelo menos ajudá-lo, a prestar a si mesmo contas do significado último de sua própria conduta (...). E creio que ele estará mais capaz de realizar isso na medida em que evitar conscienciosamente o desejo de impor ou sugerir, pessoalmente, à sua audiência a posição que tomou" (Weber, 1971, p. 179).

Paradoxalmente, apesar de aceitar que a ciência se assenta em pressupostos que não podem ser fundados cientificamente, Wcber afirma que ao se eleger a ciência é dever ético sustentar a integridade intelectual. Traduzindo em termos práticos, Weber resolve a tensão entre valores e ciência ou, mais especificamente, entre política e ciência defendendo, em resumo, que:

- os cientistas sociais devem reprimir toda a afirmação de valor na prática de sua profissão ou quando publica os resultados do seu trabalho;

- o cientista social não deve professar nenhum tipo de avaliação moral ou estética ("avaliação" no sentido de distinguir objetivamente entre o verdadeiro e o falso é permitido);

- as éticas que regem as esferas da ciência e da política são incompatíveis;

- todos os valores políticos e éticos concebíveis (liberdade, igualdade e justiça) são de igual valor, não cabendo à ciência concordar em sobrepor um sobre os outros;

- valores e avaliação dos atores sociais não são assunto da ciência social. 
Descritos os postulados que devem orientar as ciências socias, nota-se que a idéia forte é de uma ciência livre de juízos de valor. Temos aí um ponto de contato entre Weber e os positivistas. Porém, não vai além disto. O limite de tal relação fica bastante claro quando Weber explicita seus princípios epistemológicos, em texto escrito cerca de quinze anos antes de $A$ Ciência como Vocą̧ão. $\operatorname{Em} A$ Objetividade do Conbecimento nas Ciências $e$ na Política Sociais, o autor aborda duas questões interrelacionadas: tenta responder em que medida a afirmação de valores continua a manter-se no terreno da ciência e em que sentido existem verdades objetivamente válidas no âmbito da vida cultural. Busca, em outras palavras, abordar um tema bastante debatido na época, ou seja, a relação entre ciências naturais e sociais. Seu objetivo é delimitar a esfera da ciência da do juízo de valor. Veremos que se certa dubiedade já aparecia internamente ao texto tratado no tópico anterior, quando o comparamos com as elaborações epistemológicas de Weber, a sua postulação de uma ciência livre de juízos de valor fica de difícil sustentação.

Inicia seu trabalho afirmando as mesmas idéias que reelabora uma década e meio depois. Os valores são de natureza polêmica e não têm nenhuma medida objetiva ou estatuto científico. Segue-se, portanto, a necessidade de distinguir claramente entre reflexão científica e expressão de vontade. Não que não se deva eleger valores, o que Weber repele é a mistura de "ciência dos fatos" e "raciocínio axiológico".

Reconhece, porém, que tal empreitada é complexa. Numa demonstração de ambigüidade, afirma que a tomada de posições valorativas em relação aos problemas práticos não podem ser completamente sufocadas, mesmo ao nível de pesquisa puramente teórica (Weber, 1968, p. 28). Porém, apesar do fato de que "as concepções pessoais do mundo costumam intervir ininterruptamente na argumentação científica" (1968, p. 17), o cientista deve esforçar-se no sentido da maior 'objetividade'. 
A contradição de Weber se mostra mais clara quando busca definir a natureza do objeto da ciência social. Ao contrário de Marx e Durkheim, por exemplo, para Weber os fatos não têm o status epistemológico de realidades que transcendem a consciência dos sujeitos. Enquanto o "fato social" (Durkheim) ou a "condição material" (Marx) se impõe ao arbítrio das pessoas, para Weber a realidade não transcende a consciência dos atores nela envolvidos: a vida se manifesta em nós sob uma infinita diversidade de acontecimentos sucessivos e simultâneos, que aparecem e desaparecem. Segue-se que "não existe qualquer análise científica 'objetiva' da vida cultural, ou das 'manifestações sociais' que seja independente de determinadas perspectivas especiais e parciais" (Weber, 1968, p. 46)

Então, enquanto para Marx e Durkheim, a despeito de suas diferenças, a realidade se apresenta objetivamente fora do sujeito, dependendo de um enfoque cognitivo adequado para ser captada, para Weber o analista é parte ativa na constituição do próprio objeto. Isto porque
"todo o conhecimento reflexivo da realidade infinita realiza- da por um espírito humano finito se baseia na premissa tácita de que apenas um fragmento limitado dessa realidade poderá constituir de cada vez o objeto de compreensão científica, e de que só ele será essencial no sentido de ser digno de ser co- nhecido" (Weber, 1968, p. 48).

A pergunta que brota imediatamente é sob que princípio se escolhe esses fragmentos? A realidade vira objeto na medida em que possui significação para o analista, responde Weber. A significação da estrutura de um fenômeno cultural pressupõe a relação do fenômeno com idéias de valor: estas são, premissas para que algo se torne objeto de análise (1968, p. 54). E a significação não interfere apenas no recorte do objeto. $\mathrm{Na}$ explicação causal, o número e a natureza das causas que determinaram qualquer acontecimento individual são sempre infinitos, sendo 
impossível realizar a regressão que esgote o universo causal envolvido em um fenômeno. Então, também na imputação das causas de um fenômeno, deve-se escolher determinados aspectos de uma realidade infinita.

Dada a situação caótica da realidade, Weber vai propor o conceito de "tipo ideal" como instrumento para permitir a investigação e compreensão objetiva dos fenômenos sociais. A realidade social só pode ser conhecida quando aqueles traços seus que interessam intensamente ao pesquisador são metodicamente exagerados, visando permitir clareza na formulação das questões relevantes sobre as relações entre os fenômenos observados. Um "tipo ideal" consiste, pois, em enfatizar mentalmente determinados traços da realidade até concebê-los na sua expressão mais pura, que jamais se apresenta assim nas situações efetivamente observáveis. É um conceito puramente ideal, em relação ao qual se mede a realidade a fim de estabelecer o conteúdo empírico de alguns de seus elementos importantes - importantes aqui no sentido de sua rclevância significativa para o analista.

A epistemologia de Weber resulta, em sua busca de "destacar a linha quase imperceptível que separa a ciência da crença" (1968, p. 108), na idéia de que cabe a ciência fornecer "conceitos e juízos que não constituem a realidade empírica nem podem reproduzi-la, mas que permitem ordená-la pelo pensamento de modo válido" (Weber, 1968, p. 108). E que a possibilidade de conhecimento nas ciências sociais "se liga à utilização ininterrupta de pontos de vista de caráter especificamente particular que, em última análise, se encontram alinhados sobre ideais de valor" (Idem, p. 108).

Apesar da objetividade nas ciências sociais só ser possível se fundada em bases axiomáticas valorativas, isto não implica a impossibilidade de sua validade (1968, p. 109).

Deixando de lado a análise mais detida da dubiedade das afirmações Weberianas, vale algumas breves palavras sobre sua tese central. $\mathrm{O}$ 
objetivo não é criticar a forma como Weber encara o objeto das ciências sociais. Em relação a Marx e Durkheim, por exemplo, as idéias de Weber referentes ao assunto são muito mais elaborados e plausíveis. Ao contrário, pode-se afirmar que, no geral, as idéias de Weber sobre o conhecimento nas ciências sociais são irrefutáveis. $O$ problemas que se deve destacar é a total falta de compatibilidade da sua proposta de uma ciência "livre de valores", com sua epistemologia. Tal proposta enquadra-se muito melhor na epistemologia de Durkheim e mesmo, em menor grau, na de Marx. Se não há um mundo objetivo a ser captado de forma isenta, como propor que o conhecimento não traga implícito em suas conclusões os valores que informam toda a problemática inicial? Vejamos como outros autores abordam estas questões.

\section{IV}

A contradição revelada por Weber no tratamento da relação entre ciência e valores, naturalmente não passa despercebida a outros autores. Aron, por exemplo, busca apontar contradições na obra do autor alemão. Chama a atenção que quando Weber caracteriza o chefe carismático em contraposição ao demagogo, ressaltando seu respeito pelo primeiro e o sentimento oposto em relação ao outro, está professando juízos de valor que ignora em sua epistemologia explícita. No mesmo sentido, Mészáros vai apontar no "caráter inteiramente estático dos tipos ideais de Weber” uma fonte de juízos de valor (Mészáros, 1993, p. 31). Por exemplo, a burocracia por ser indispensável à sociedade moderna não pode assim ser considerada indefinidamente.

O próprio Aron busca, de forma implícita, se valer da contradição Weberiana. Ao se defrontar com uma crítica à posição de Weber de retirar os juízos de valor da esfera da ciência, afirma: 
"na narração ou interpretação dos acontecimentos ou das obras o historiador não pode deixar de incluir juízos de valor, na medida em que estes são internos ao universo da ação e do pensamento, constitutivos da própria realidade" (Aron, 1986, p. 46).

Ou seja, expressa uma posição que refuta a idéia Weberiana. No entanto, ressalta adiante que sua crítica a Weber é suscetível de ser integrada no pensamento do autor alemão. E, na verdade, o é; dada a convivência de afirmações contraditórias em sua obra.

Vejamos, porém, com mais vagar, a explicação que Gouldner oferece para tal dubiedade e as críticas que faz à proposição Weberiana. Seu enfoque não visa a lógica do argumento de Weber, mas baseia-se na abordagem típica da sociologia do conhecimento. Inicia lançando mão da figura do minotauro como forma de expressar a tentativa, que considera absurda, de cindir o homem de valores do homem de ciência. E os motivos que fizeram com que Weber desse vida a esse ser mitológico eram eminentemente práticos. O cerne da tese do autor é o seguinte:

"A necessidade que uma ciência social axiologicamente neutra supre é tanto pessoal quanto institucional. Resumidamente, minha tese é que entre os principais fatores de sobrevivência e difusão do mito do value-free está sua função de manutenção da coesão e autonomia da universidade moderna, em geral, e da disciplina da ciência social, em particular. É fácil demonstrar que estes estavam entre os motivos originais que induziram Max Weber a formular a concepção de uma sociologia livre de juízos de valor" (Gouldner, 1992, p. 6-7).

Na universidade alemã, o fato de que os professores que expressavam valores obtinham mais alunos, e em conseqüência maior remuneração, redundava em que os professores atrativos eram privilegiados $\mathrm{e}$ os bons professores penalizados. Ao buscar retirar os valores da esfera da ciência, Weber estava, segundo Gouldner, buscando restringir a competição dentro da universidade e com isto promover um ambiente 
de paz. Ou seja, "sob essas condições históricas, a doutrina do value-free era uma proposta que visava uma trégua acadêmica" (Gouldner, 1992, p. 8).

Além disto, prossegue o autor, Weber temia que a expressão de valores políticos na universidade implicasse em censura do Estado e perda da autonomia universitária. Visava, portanto, despolitizar o ambiente acadêmico, o que, de resto, estava de acordo com o nacionalismo Weberiano, cujo objetivo era o fortalecimento do poder do Estado Alemão.

Para Gouldner, o resultado da proposta de Weber foi paradoxal. Por um lado, permite o aumento da autonomia da Sociologia, que se liberta de constrangimentos impostos pela sociedade: na Europa da influência dos partidos políticos, e nos EUA do Poder Executivo. Ajuda, assim, a demarcar o campo das ciências sociais dos interesses políticos, por exemplo. Por outro, porém, cria condições para a desorientação de padrões e indiferença moral. Torna-se álibi para que alguns aproveitem para perseguir seus impulsos privados e omitir-se das responsabilidades públicas, sob a capa do profissionalismo e anticriticismo que escondem interesses privados e egoístas. É o caso característico dos EUA, por exemplo.

Em caráter mais geral, Gouldner afirma que a perspectiva de Weber descansa sobre o dualismo entre, de um lado, razão e racionalidade, personificada na burocracia e ciência e, de outro, nas forças emocionais mais elementares, expressada na noção de carisma. Weber vê estas forças como inimigas entre si e, ambas, ao mesmo tempo necessárias e perigosas. A razão e a emoção são dois pólos considerados por Weber que, no entanto, não consegue relacioná-los. Busca, então, resolver o dilema pela estratégia da segregação, através da exclusão da irracionalidade carismática das modernas instituições, como a universidade. Mas, por outro lado, admite e exalta estas manifestações na vida pessoal e íntima dos 
indivíduos. Ao buscar solução para a competição da razão e fé, propõe a autonomia de ambas as esferas.

Gouldner afirma que Weber acerta ao levantar o problema, mas discorda da solução que oferece. Indaga, com razão: se os sociólogos devem evitar expressar seus valores pessoais na sua cátedra, como então os estudantes se defendem contra a influência inconsciente que esses valores fornecem quando estão na base da seleção dos problemas, hipóteses e esquemas conceituais? Propõe, corretamente, que se deve expor claramente como a ciência é feita, e não mitificá-la. Além da proficiência técnica do estudante, deve-se atentar para o seu senso moral. Não se trata de minimizar a objetividade científica, mas insistir que ela difere radicalmente de uma moral indiferente.

Em que pese o acerto da conclusão geral de Gouldner, seu texto merece alguns reparos. Em primeiro lugar, este autor não se preocupa em indicar os fundamentos de suas conclusões sobre as intenções ou objetivos de A Ciência como Vocação. Aí deve-se ressaltar a contradição dos objetivos de Weber, na versão de Gouldner, com o próprio conteúdo de seu trabalho. Caso seja verdadeira a tese de Gouldner, Weber estaria agindo na esfera da ciência segundo a ética própria da esfera política, ou seja, a ética de resultados. O texto objetivaria não verdades científicas, mas sim causar certos efeitos práticos. A pergunta que fica é: será que Weber utilizaria o artifício que critica no próprio texto?

Finalmente, cabe notar que os efeitos da proposta de uma ciência neutra de valores apontados por Gouldner são interessantes e provavelmente reais, mas deve-se ressaltar que não têm ligação necessária com as intenções iniciais de Weber. As afirmações de Gouldner valem apenas no sentido de mostrar como certas posturas epistemológicas podem servir para legitimar certos interesses. 


\section{V}

Como vimos, Weber concebe a realidade como infinita. Sendo assim, ao selecionar os aspectos da realidade que irão conformar o objeto de análise e as questões cujas respostas deverão ser dadas, o que orienta o trabalho científico são os valores do pesquisador. Contraditoriamente, porém, Weber afirma que no momento da resposta a ciência social deve ser axiologicamente neutra ou livre de juízos de valor, orientando-se por regras objetivas e universais. Ou seja, tenta conciliar pressupostos subjetivos da pesquisa com resultados objetivos.

A verdade é que os juízos de valor encontram-se tanto na seleção do objeto e da problemática como na resposta oferecida. Isto porque a própria problemática já define, em boa medida, o conteúdo da investigação científica, pois a formulação da pergunta contém, em certo sentido, a própria resposta. Nestes termos, se os valores estão implícitos na formação dos tipos ideais, é natural que influenciem também o resultado final do trabalho científico.

Weber reconhece o problema de forma tímida. Afirma que as concep̧ões pessoais intervêm a todo o momento no trabalho das ciências sociais. A forma que encontra para escapar a esta constatação, no seu intento de defender a ciência axiomaticamente neutra de valores, é tomar tal interferência como fraqueza humana. A solução que oferece é recomendar o autocontrole científico, o que é frágil, pois não oferece nenhuma concepção metodológica que sustente tal objetivo. Ironicamente, Weber tenta se livrar de um aspecto do trabalho científico que ninguém melhor do que ele próprio demonstrou em suas idéias sobre epistemologia das ciências sociais.

O que Weber faz bem é expressar um dilema, que pode ser colocado, de um lado, na situação do analista que registra a realidade tal qual ela é, em sua pureza objetiva, e, por outro lado, o objeto do 
conhecimento resultando do arbítrio soberano da subjetividade do sujeito cognoscente, ou em sentido figurado, uma espécie de autismo intelectual. É óbvio que os extremos não são convincentes, mas ilustram de alguma forma componentes que estão presentes na investigação científica e que têm de ser compatibilizados de alguma forma: o objetivo e o subjetivo, a ciência positiva e os julgamentos de valor.

A solução que Weber oferece para tal dilema não é a mais recomendada. Propõe a cisão das esferas dos valores e da ciência, que por princípio teimam em se contaminar. Utilizando a imagem proposta por Gouldner, propõe a criação de algo fictício: o minotauro. Porém, está certo em seu esforço de buscar a maior objetividade possível. Apenas o caminho é que cremos não ser o melhor. Ao invés de buscar negar a realidade, deve-se portanto, é clarear a perspectiva a partir da qual construímos o trabalho científico. Ou seja, devemos ter a consciência possível do que significam nossas questões e problemas. Por outro lado, a busca de um grau maior de objetividade depende da livre circulação das idéias científicas que, ao exigir que os postulados científicos sejam colocados de forma objetiva e que os valores envolvidos sejam contrapostos a outros, acabam por possibilitar consensos e expor fragilidades lógicas de certas pressuposições ou explicitar valores que se escudam no rótulo de ciência.

Qualquer ciência, então, é função de duas variáveis: a busca da adequação conceitual visando captar problemas relevantes de um pontode-vista extracientífico, e a busca da precisão na definição do sistema de pensamento e da relação entre os conceitos estabelecidos. Por outro lado, a preocupação excessiva com a procura da objetividade redunda em classificação de coisas irrelevantes e, por outro, a preocupação extrema com a relevância social ou normativa leva ao desprezo pelos procedimentos de verificação, confirmação e consistência (Schwartzman, 
1971). O ideal é alcançar o máximo de objetividade com o máximo de relevância.

Há, assim, relação entre conhecimento comum e conhecimento obtido pelo método científico. A melhor forma de abordar tal relação é assumir o fato de que ambos os conhecimentos se influenciam. $\mathrm{O}$ conhecimento científico nega ou corrige o conhecimento comum, e este incorpora alguns resultados daquele. Cremos, pois, que a solução para a dicotomia ciência e valores não é tentar cindir os dois aspectos, mas relacioná-los dialeticamente. $\mathrm{Na}$ verdade, há relação sociológica entre fatos e valores. O conhecimento dos fatos pode levar a opções políticas ou morais e estas, por outro lado, estão presentes na abordagem dos fatos.

Pode-se concluir, então, que todo o conhecimento humano guarda seus laivos de subjetividade. As teses teóricas são sempre socialmente condicionadas mas, apesar disto, têm o valor de verdades relativas, ninguém melhor que Weber mostrou a impossibilidade de verdades absolutas. São, portanto, verdades que buscam o maior grau de objetividade, susceptíveis de se desenvolverem e aperfeiçoarem, tanto mais, quanto maior e mais livre é o debate entre os participantes do jogo da ciência.

\section{BIBLIOGRAFIA}

ARON, R. "Introducción". In: Weber, M. El politico y el científico. Madrid, Alianza Editorial, 1986.

GOULDNER, A. W. For Sociology: Renewal and critique in sociology today. New York, Basic Books Inc. Publishers, 1992.

KASLER, D. Max Weber: An Introduction to bis life and Work. The University of Chicago Press, 1979. 
LASSMAN, P. e VELODY, I. Max Weber's: "Science As a Vocation". London, Unwin Hyman, 1989.

LÖWY, M. Ideologia e Ciência Social. São Paulo, Cortez Editora, 1986.

MÉSZÁROS, I. Filosofia, ideologia e ciência social. São Paulo, Ed. Ensaio, 1993.

SCHWARTZMAN, S. O dom da eterna juventude. Revista Dados, IUPERJ, Rio de Janeiro, 1971.

WEBER, M. A objetividade do conbecimento nas ciências e nas políticas sociais. Lisboa, Editorial Presença, 1968.

"A ciência como vocação". In: Weber, M. Ensaios de sociolo. gia. Rio de Janeiro, Zahar Editores, 1971. 
